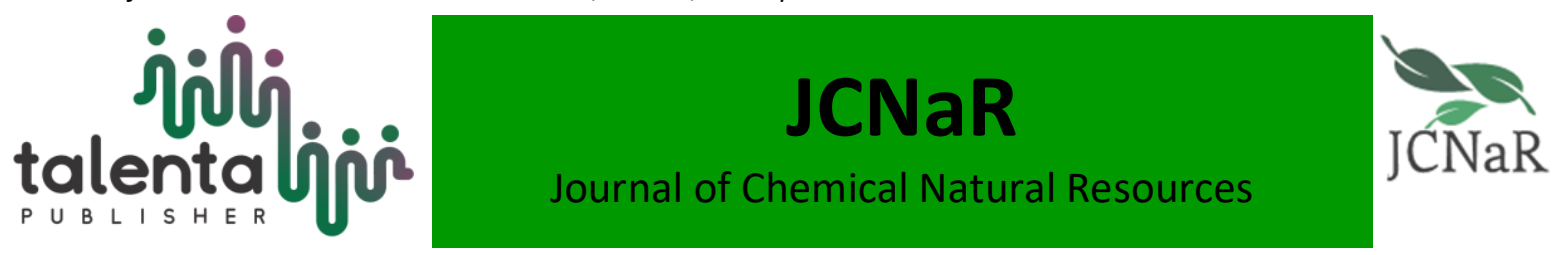

\title{
Synthesis Of 4-Alil-6- (Hydroxymethyl) -2-Methody Phenol Compounds from Eugenol Through Mannich Reaction Followed Methylation with Methyl Iodide and Substitution Using $\mathrm{NaOH}$
}

\author{
Sabarmin Perangin-angin ${ }^{1 *}$, Darwis Surbakti ${ }^{2}$,Jodi Pratama Siahaan ${ }^{3}$ \\ ${ }^{1,2,3}$ Department of Chemistry, Faculty of Mathematics and Science, Universitas Sumatera Utara \\ Jalan Bioteknologi No.01 Kampus USU Medan 20155
}

\begin{abstract}
Eugenol derivative compound 4-allyl-6-hydroxymethyl-2-methoxy phenol was synthesized through Mannich reaction, methylation, dan nucleophilic substitution. Mannich reaction was carried out by reacting eugenol, formaldehyde 37\%, and dimethylamine $40 \%$ in reflux condition with n-heptane solvent at temperature $98-100^{\circ} \mathrm{C}$ for 10 hours produced 4-allyl-6-(dimethylamino)methyl-2-methoxy phenol with yield of $83 \%$. The formation of dimethylaminomethyl group supported by C-N stretching vibration at $1246.16 \mathrm{~cm}-1$ and ion molecule peak at 221 in GC-MS analysis. Methylation of4-allyl-6(dimethylamino)methyl-2-methoxy phenol was carried out with methyl iodide in ethanol solvent produced 6-((N-iodo-N-methyl-N-methyl-N-methylamino) methyl)-4-allyl-2methoxy phenol in solid form, which then purified by recrystallization with $78.15 \%$ yield. 4-allyl-6-(hydroxymethyl)-2-methoxy phenol was synthesized by nucleophilic substitution reaction of 6-((N-iodo-N-methyl-N-methyl-N-methylamino)methyl)-4-allyl-2-methoxy phenol with sodium hydroxide in reflux condition then purified by coloum chromatography gave liquid compound with yield of $65.05 \%$. The formation of hydroxymethyl group supported by $\mathrm{OH}$ vibration at $3433.9 \mathrm{~cm}^{-1}$ and ion molecule peak at 194 in GC-MS analysis show the relative molecular mass of synthesized product.
\end{abstract}

Keyword:Eugenol, Mannich Reaction, Methylation, Nucleophilic Subtitution, 4-allyl-6hydroxymethyl-2-methoxy phenol.

Received November 5, 2018| Revised December 19, 2018 | Accepted January 23, 2019

\section{Introduction}

Eugenol is the main component contained in clove oil (Syzygium aromaticum) with a content of 70-96\% which is a clear liquid to pale yellow with a refreshing and spicy aroma such as dried clove flowers, giving a distinctive aroma to clove oil (Kardinan, 2005).Eugenol is a phenolic compound that has several functional groups such as allyl, hydroxide and methoxy. With the existence of these functional groups, eugenol compounds can be transformed into several derivative compounds that are directly useful or become the basic material for the manufacture

\footnotetext{
*Corresponding author at:Department of Chemistry Faculty of Mathematics and Science Universitas Sumatera Utara, Medan, Indonesia

E-mail address: sabarminp@yahoo.com
} 
of other compounds. Some eugenol derivatives that have been carried out are alkylation, addition, isomerization, acetylation, esterification, polymerization, monoetheric cyclization and etc. (Suryanto and Anwar, 2008).

Research with eugenol materials has been frequently conducted, especially for eugenol derivatives such as the transformation of allyl groups in eugenol into aldehyde groups in vanillin which are used as additives in food, as well as the transformation of hydroxyl groups into alkyl, acyl or acetyl from eugenol derivatives such as methyl eugenol, eugenil benzoate, and acetyl eugenol which can be used as bio-additive substances for diesel fuel (Sastrohamidjojo, 2004).

Eugenol is widely used in dentistry, anesthesia, analgesics, anti-swelling agents, and antioxidants. Phenol compounds have important antioxidant activity because they can capture oxygen atoms from alkyl radicals in the oxidized group by giving one hydrogen atom from the phenolic hydroxyl group. Some research results from the antioxidant function of eugenol show eugenol antioxidant function similar to most phenol derivatives (Kong et al., 2014).

Mannich reactions are used in the synthesis of natural compounds such as peptides, nucleotides, antibiotics and alkaloids. Some of the drugs produced from the Mannich reaction are proven to be more effective and less toxic than the original parent compound. Based on Mannich's application of pharmaceutical products some researchers have synthesized several phenolic phenol bases from naphthol and cresol and showed anti-bacterial activity (Kousar et al., 2013). Karanov et al.(1995) synthesized the 2-methoxy-4- (1-propenyl) -6-substituted phenol compound through the Mannich reaction by reacting eugenol, formaldehyde, and amine compounds indicate the activity of plant growth regulators. According to research conducted by Mastelic et al. (2008) hydroxymethyl timol, carvacrol, and eugenol derivatives that were synthesized through hydroxymethylation reaction showed better antioxidant activity than the initial compound and the activity value was almost the same as butylated hydroxy toluene (BHT) and vitamin C with yield result obtained as much as $51 \%$.

\section{Materials and Methods}

In this study, the tools used are a set of spectrophotometry IR Shimadzu, Radwag Analytical Scale, thermometer, Reflux Tool Series, chromatographic column, separating funnel, volumetric flask, erlenmeyer, and measuring cup.

The ingredients used in this study were Eugenol (Biodinamica), dimethylamine 40\%, formaldehyde $37 \%, \mathrm{HCl} 1 \mathrm{~N}, \mathrm{n}$-heptane, n-hexane, ethyl acetate, potassium iodide, $85 \%$ phosphoric acid, methanol, ethanol, diethyl ether, aquadest, $\mathrm{NaOH}$ pellet, $5 \% \mathrm{Na}_{2} \mathrm{~S}_{2} \mathrm{O}_{3}$ and anhydrous sodium sulfate. 


\subsection{The Making of 4-alyl-6- (dimethylamino) methyl-2-methoxy phenol Compounds}

A total of 4.85 grams $(0.03 \mathrm{~mol})$ of eugenol wasinserted into the three-neck flask. Then a mixture of 3.8 grams $(3.48 \mathrm{~mL})$ formaldehyde $37 \%$ and 5.6 grams $(0.05 \mathrm{~mol})$ dimethylamine $40 \%$ was added. About $20 \mathrm{~mL}$ of $\mathrm{n}$-heptane was added into previous solution and refluxed at a temperature of $98-100^{\circ} \mathrm{C}$ while being stirred for 10 hours. The result of reflux was inserted to the separating funnel, then it was extracted with diethyl ether and set aside to form two layers. The top layer was then dried with anhydrous $\mathrm{Na}_{2} \mathrm{SO}_{4}$. Excessive solvents wereevaporated, and result was obtained.

\subsection{The Making of Methyl Iodide $\left(\mathrm{CH}_{3} \mathrm{I}\right)$}

Sample as much as 66.4 grams $(0.4 \mathrm{~mol})$ of potassium iodide were dissolved with $175 \mathrm{~mL}$ (3 moles) of phosphoric acid in a three-neck flask then added with $120 \mathrm{~mL}$ ( 3 moles) of methanol. Then the distillation device is strung together, and stirred using a magnetic stirrer while being slowly heated. The distillate was collected in the cooled flask and stopped after the distillate temperature reached $65^{\circ} \mathrm{C}$. Put in a separate funnel and extracted with $5 \% \mathrm{Na}_{2} \mathrm{~S}_{2} \mathrm{O}_{3}$ solution which will form two layers. The bottom layer is taken and washed again with aquadest which will form two layers as well. The lower layer was dried using anhydrous $\mathrm{Na}_{2} \mathrm{SO}_{4}$ and the results obtained were analyzed using IR spectrophotometer and GC-MS.

\subsection{The Making of (6 - ((N-iodo-N-methyl-N-methyl-N-methylamino) methyl) -4-allil-2- methoxy phenol)}

A total of 4.404 grams (20 mmol) of 4-alyl-6-(dimethylamino)methyl-2-methoxyphenol compounds are inserted into the Erlenmeyer container. About $35 \mathrm{~mL}$ ethanol was added and methyl iodide was added as much as 2.84 grams $(20 \mathrm{mmol})$ and the container was closed tightly. The reaction mixture is stirred at room temperature with a magnetic stirrer for 2 hours and left in the refrigerator overnight. The formed precipitate was filtered using filter paper and washed with diethyl ether. The obtained results were purified by recrystallization using ethanol.

\subsection{The Making of 4-Alyl-6-(hydroxymethyl) -2-methoxyphenol Compound}

A total of 3.621 grams $(0.01 \mathrm{~mol})$ of compounds $(6-((\mathrm{N}-$-iodo-N-methyl-N-methyl-Nmethylamino) methyl) -4-allil-2-methoxy phenol) were inserted into the three-neck flask. $50 \mathrm{~mL}$ of aquadest was added and stirred for one hour. In the mixture a solution of 1.6 grams $(0.04$ mol) of $\mathrm{NaOH}$ was added in $20 \mathrm{~mL}$ of aquadest through a dropper funnel and the mixture was refluxed for 2 hours at $100^{\circ} \mathrm{C}$. The results were neutralized using $1 \mathrm{~N} \mathrm{HCL}$ to $\mathrm{pH} 7$ and put into the separating funnel. Then was extracted using diethyl ether solvent, diethyl ether layer was dried using anhydrous sodium sulfate and diethyl ether solvent was evaporated. The obtained residue was purified by column chromatography using the silica gel stationary phase and nhexane/ ethyl acetate eluent in a ratio of 3: $2 \mathrm{v} / \mathrm{v}$. The obtained results were analyzed by IR spectrophotometer and GC-MS. 


\section{Results and Discussion}

\subsection{4-alil-6- (dimethylamino) methyl-2-methoxy phenol Compound}

The obtained compounds of 4-alyl-6-(dimethylamino)methyl-2-methoxy phenol were 5.06 grams $(83 \%)$, in the form of black liquid. The obtained data from IR spectrophotometer analysis of 4-alyl-6-(dimethylamino)methyl-2-methoxy phenol compounds were as follows:

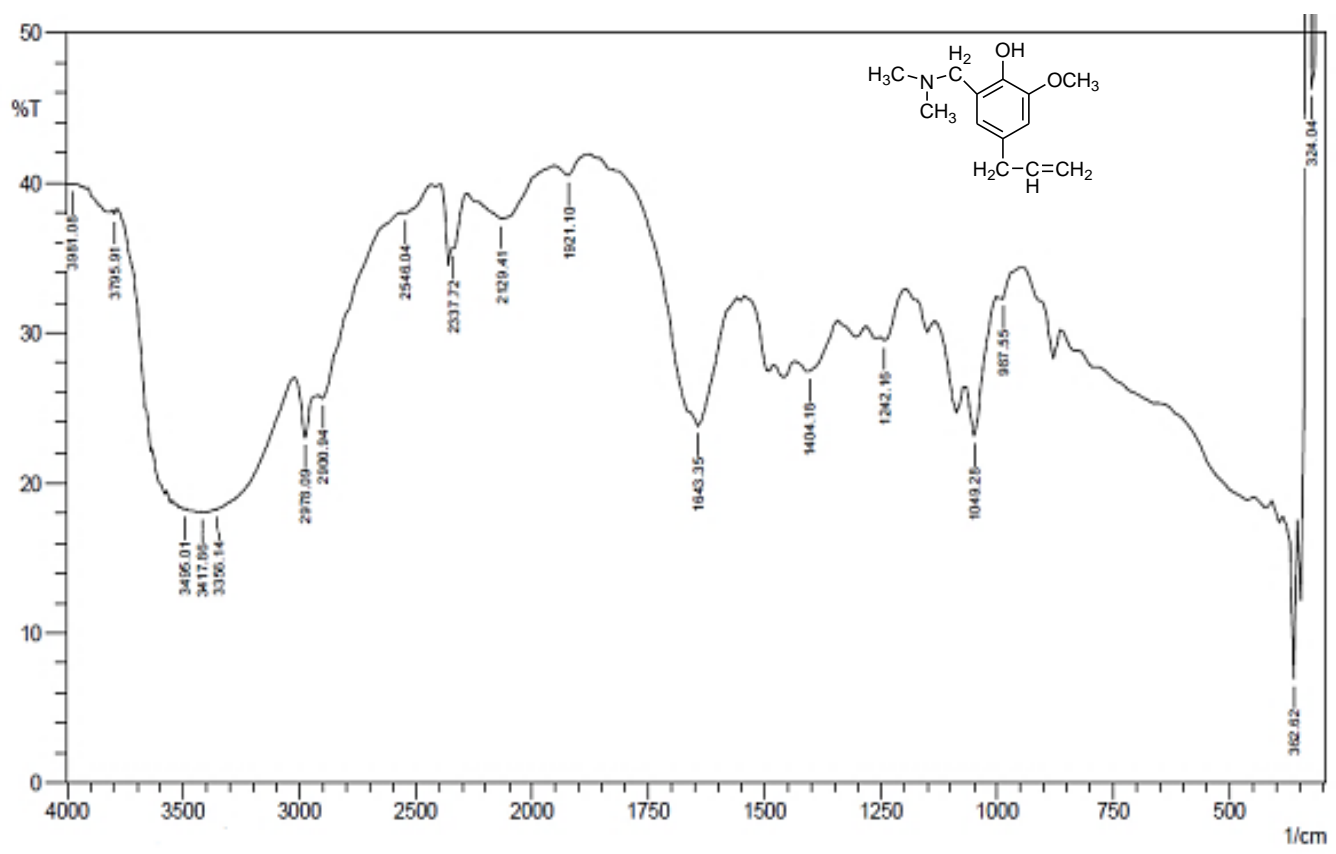

Figure 3.1 FT-IR spectra of 4-alil-6-(dimethylamino)methyl-2-methoxyphenol

The FT-IR spectrum shows that the 4-alil-6-(dimethylamino) methyl-2-methoxy phenol compound formed has a $\mathrm{CN}$ bond derived from dimethylaminomethyl groups with the presence of $\mathrm{C}-\mathrm{N}$ stretching vibration in the wave number $1242.16 \mathrm{~cm}^{-1}, \mathrm{~N}-\mathrm{H}$ stretching vibration of tertiary amines is very weak it overlapped with $\mathrm{OH}$ vibrations that have stronger absorption. The transmittance peak at wavenumber $3417.86 \mathrm{~cm}^{-1}$ shows $\mathrm{O}-\mathrm{H}$ vibration, then it is supported in the wave number area of $2978.09 \mathrm{~cm}^{-1}$ which shows stretching vibration of $\mathrm{C}-\mathrm{H} \mathrm{sp}{ }^{2}$ (= CH-) and wave $2900.94 \mathrm{~cm}^{-1}$ indicating vibration stretch $\mathrm{C}-\mathrm{H} \mathrm{sp}^{3}$ on $\mathrm{CH}_{2}$. The transmittance peak at wavenumber $1404.18 \mathrm{~cm}^{-1}$ shows $\mathrm{CH}_{2}$, and vinyl groups are shown at $987.55 \mathrm{~cm}^{-1}$ and $\mathrm{C}=\mathrm{C}$ aromatic is shown at wave $1643.35 \mathrm{~cm}^{-1}$. 

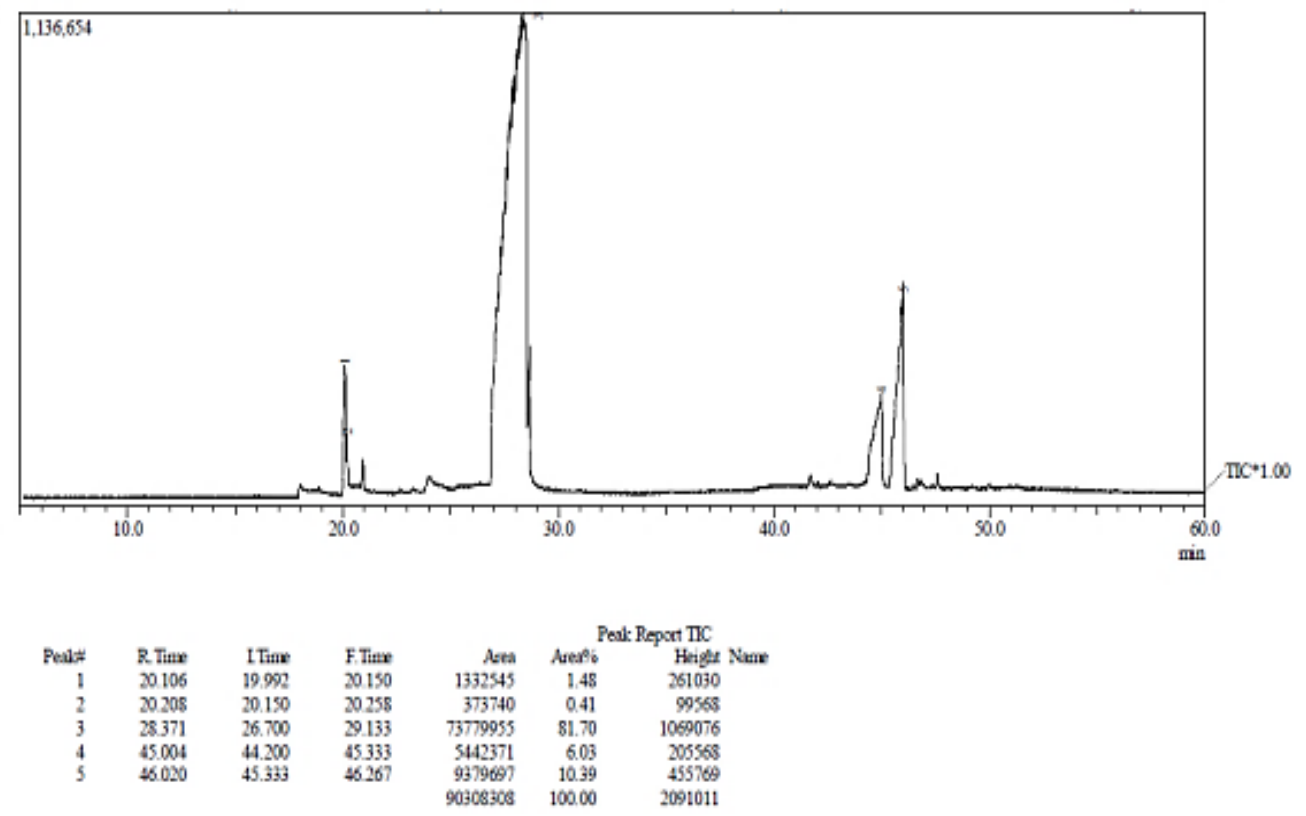

Figure 3.2 Chromatogram of 4-alyl-6- (dimethylamino) methyl-2-methoxy phenol Mass.

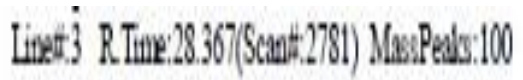

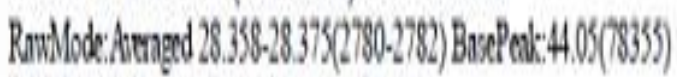 \\ BG Mode Calc foum Peak Goup 1. Evet I}

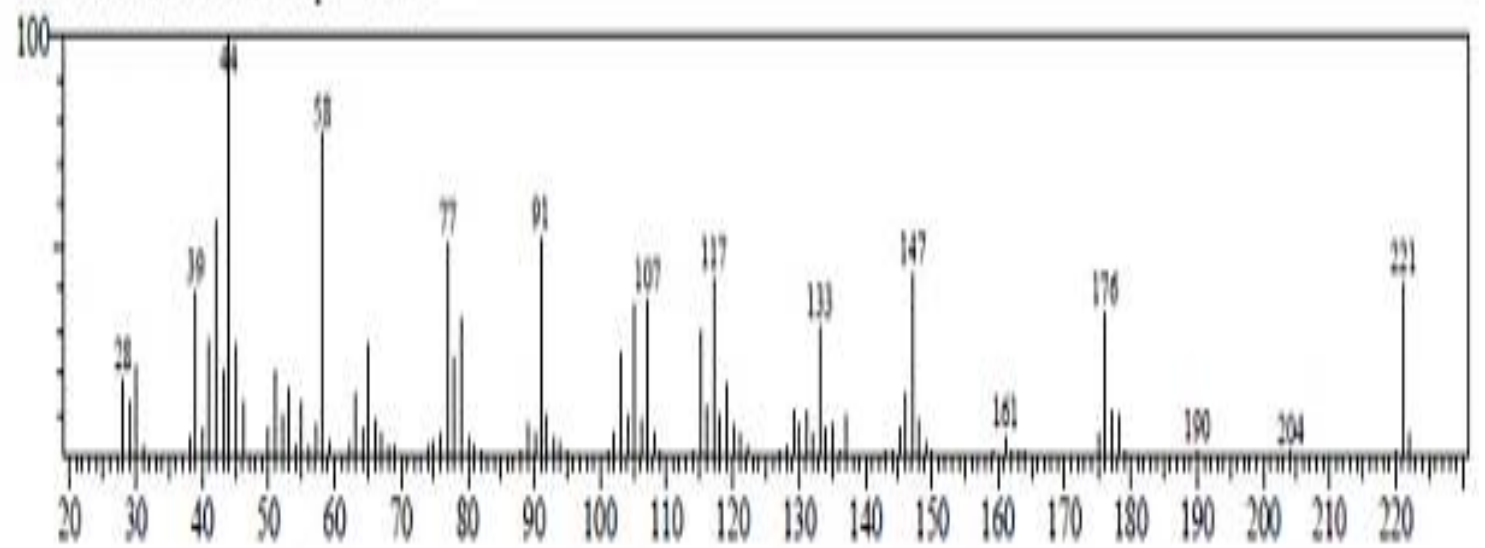

Figure 3.3 Mass Spectrum 4-alyl-6- (dimethylamino) methyl-2-methoxy phenol

GC-MS analysis shows that the synthesized compound has a peak of molecular ions of 221

followed by fragmentation peaks at m/e 204, 190, 176, 161, 147, 133, 117, 107, 91, 77, 58, 44, 39 and 28 , where this value corresponds to the relative molecular weight (Mr) of the synthesized 4-alyl-6- (dimethylamino) methyl-2-methoxy phenol compound. 


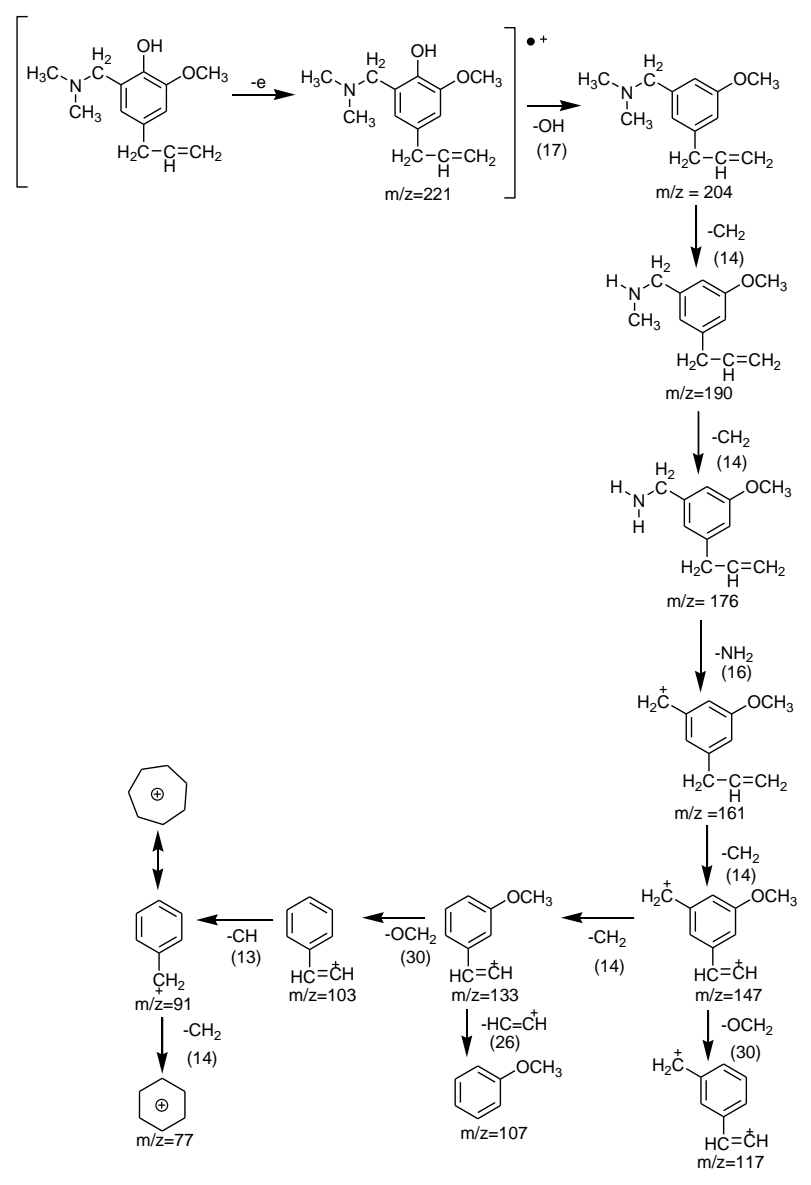

Figure 4.9 Fragmentation pattern of 4-alyl-6- (dimethylamino) methyl-2-methoxy phenol compound

\subsection{6-((N-iodo-N-methyl-N-methyl-N-methylamino)methyl)-4-alyl-2-methoxyphenol compound}

The compound of 6-((N-iodo-N-methyl-N-methyl-N-methylamino) methyl)-4-alyl-2methoxy phenol was obtained about 5.66 grams $(78.15 \%)$ and has a yellow-colored solid. The results of FT-IR spectroscopy analysis of 6-((N-iodo-N-methyl-N-methyl-Nmethylamino)methyl)-4-alyl-2-methoxy phenol is shown below: 


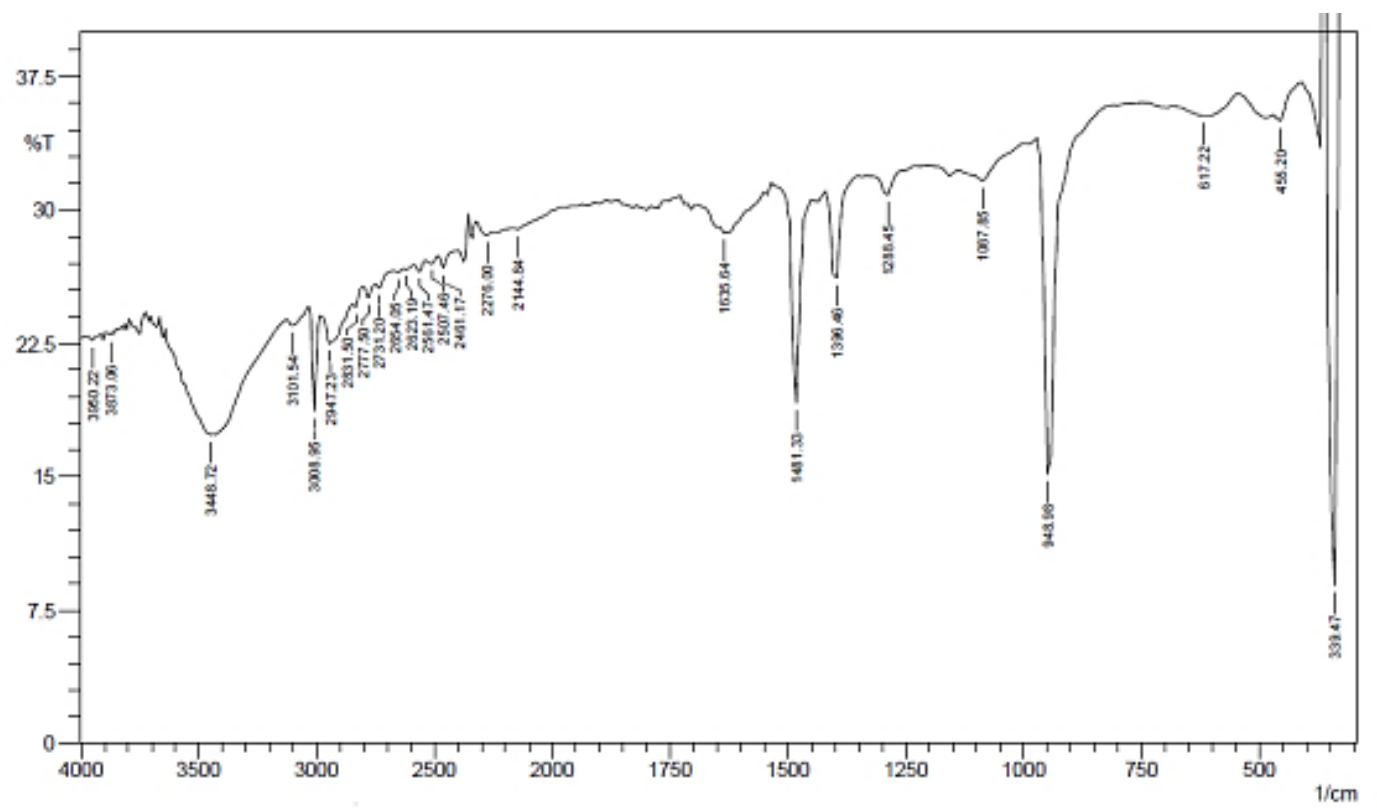

Figure 3.4. FT-IR spectrum of 6 - ((N-iodo-N-methyl-N-methyl-N-methylamino) methyl)-4alyl-2-methoxy phenol

The FT-IR spectrum of 6-((N-iodo-N-methyl-N-methyl-N-methylamino)methyl)-4-alyl-2methoxy phenolshows the stretching vibration of strong $\mathrm{C}-\mathrm{N}^{+}$from quaternary ammonium salt at wave $948.98 \mathrm{~cm}^{-1}$ and supported by the appearance of weak absorption from vibration bending $\mathrm{C}-\mathrm{N}^{+}$at wavenumbers $455.20 \mathrm{~cm}^{-1}$. These wavenumbers, 948.98 and $455.20 \mathrm{~cm}^{-1}$ are characteristic of quaternary ammonium salts which both appear simultaneously. The absorption peak at wave $3448.72 \mathrm{~cm}^{-1}$ shows $\mathrm{O}-\mathrm{H}$ vibration, then the wavenumber $3008.95 \mathrm{~cm}^{-1}$ which shows stretch vibration of $\mathrm{C}-\mathrm{H} \mathrm{sp}{ }^{2}(=\mathrm{CH}-)$ and the appearance of wavenumber at $2947.23 \mathrm{~cm}^{-1}$ which shows stretching vibration $\mathrm{CH} \mathrm{sp}{ }^{3}$ on $\mathrm{CH}_{2}$. The absorption peak at wave number 1481.33 $\mathrm{cm}^{-1}$ shows $\mathrm{CH}_{2}$ and $\mathrm{C}=\mathrm{C}$ aromatic shown in wave $1635.64 \mathrm{~cm}^{-1}$.

\subsection{4-alyl-6- (hydroxymethyl) -2-methoxy phenol compound}

The yield of 4-alil-6- (hydroxymethyl)-2-methoxy phenol compound that obtained from 3,621 grams of 6-((N-iodo-N-methyl-N-methyl-N-methylamino) methyl)-4-alil-2 methoxy phenol compound is 1.262 grams $(65,05 \%)$. The 4-alyl-6- (hydroxymethyl) -2-methoxy phenol compound has a reddish yellow liquid. 


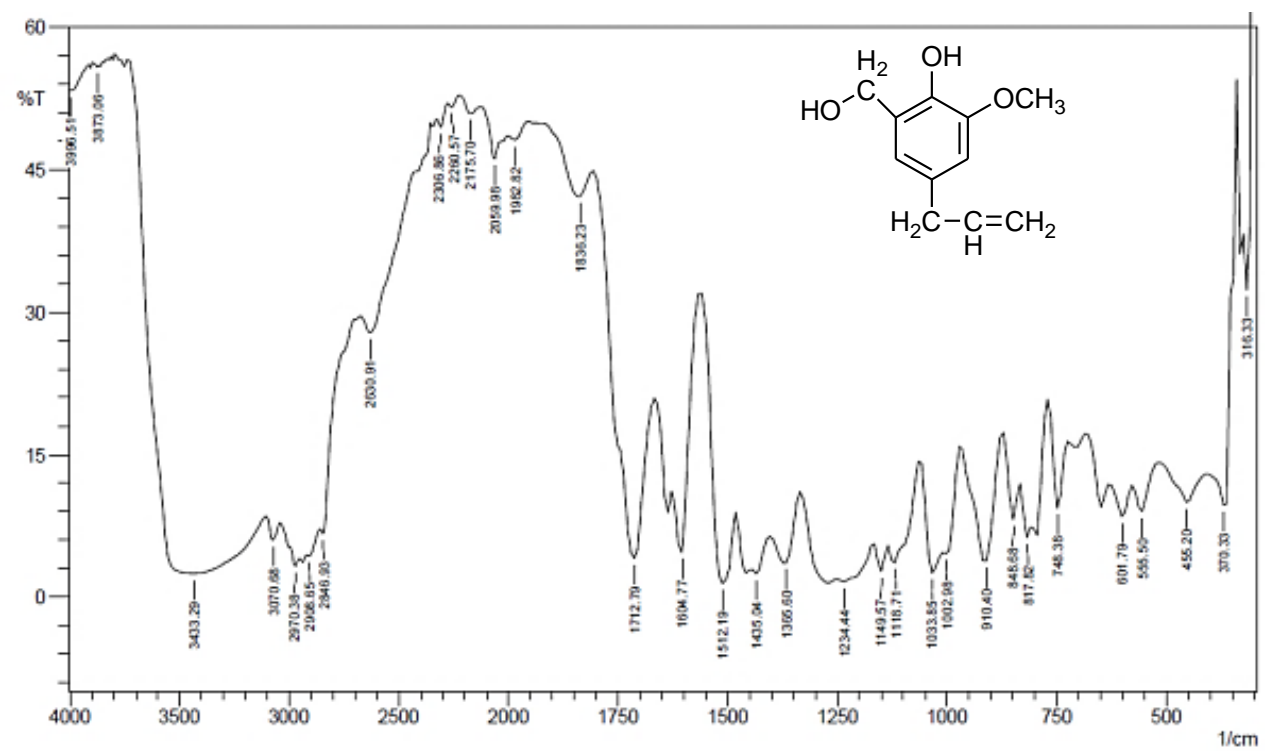

Figure 3.5. FT-IR spectrum of 4-alil-6- (hydroxymethyl)-2-methoxy phenol

The results of infrared spectrophotometric analysis (FT-IR) of 4-alyl-6- (hydroxymethyl) -2methoxy phenol shows that the vibration of $\mathrm{O}-\mathrm{H}$ at wavenumber of $3433.9 \mathrm{~cm}^{-1}$. The transmittance peak at wavenumber of $3070.68 \mathrm{~cm}^{-1}$ shows the stretching vibration of C-H sp ${ }^{2}=$ $\mathrm{CH}-$ ). The absorption peak at wavenumber of $2908.65 \mathrm{~cm}^{-1}$ shows the stretching vibration of C$\mathrm{H} \mathrm{sp}{ }^{3}$ at $\mathrm{CH}_{2}$, which is supported by wavenumber of $748.38 \mathrm{~cm}^{-1}$ indicating the bending vibration of $\mathrm{C}-\mathrm{H} \mathrm{sp}{ }^{3}$. The transmittance peak at the wavenumber of $1234.44 \mathrm{~cm}^{-1}$ shows the asymmetric C-O-C stretch vibration of the methoxy group and the wavenumber $1033.85 \mathrm{~cm}^{-1}$ which shows asymmetric C-O-C stretching vibration of the methoxy group. The transmittance peak at wave $1604.77 \mathrm{~cm}^{-1}$ shows that the $\mathrm{C}=\mathrm{C}$ aromatic group and the wave $1435.04 \mathrm{~cm}^{-1}$ indicates the stretch vibration from $\left(-\mathrm{CH}_{2}-\right)$. Absorption peak at $910.4 \mathrm{~cm}^{-1}$ wave indicate vinyl groups.

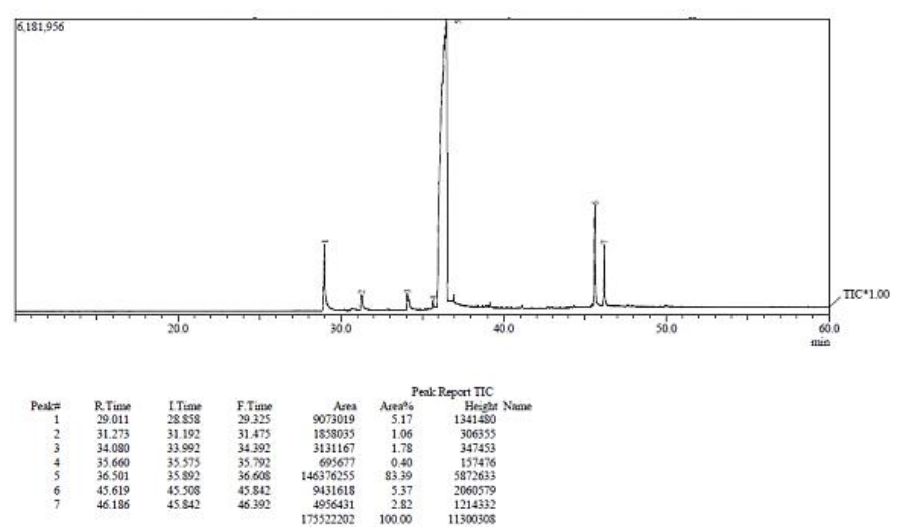

Figure 3.6 Chromatogram of 4-alyl-6- (hydroxymethyl) -2-methoxy phenol mass 


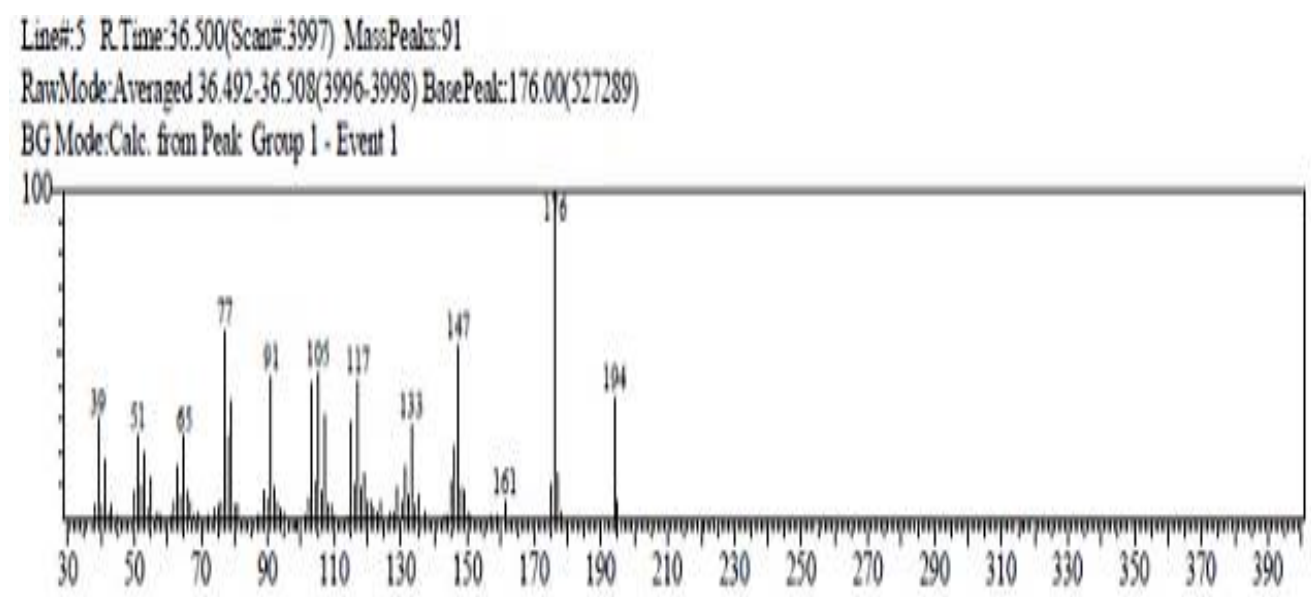

Figure 3.7 Mass Spectrum 4-alil-6- (hydroxymethyl) -2-methoxy phenol

The results of GC-MS analysis of 4-alyl-6-(hydroxymethyl)-2-methoxy phenol compounds confirmed the formation of the expected compounds. The mass spectrum shows the peak of the molecular ion at m/e 194 followed by peaks of fragmentation at m/e 176, 161, 147, 133, 117, $105,91,77,65,51$, and 39. The mass spectrum of GC-MS shows the relative molecular weight of the synthesized compound is 194 , which has the same value as the relative molecular weight of the 4-alyl-6- (hydroxymethyl)-2-methoxy phenol compound. The fragmentation pattern of 4alyl-6- (hydroxymethyl)-2-methoxy phenol compounds is as follows: 


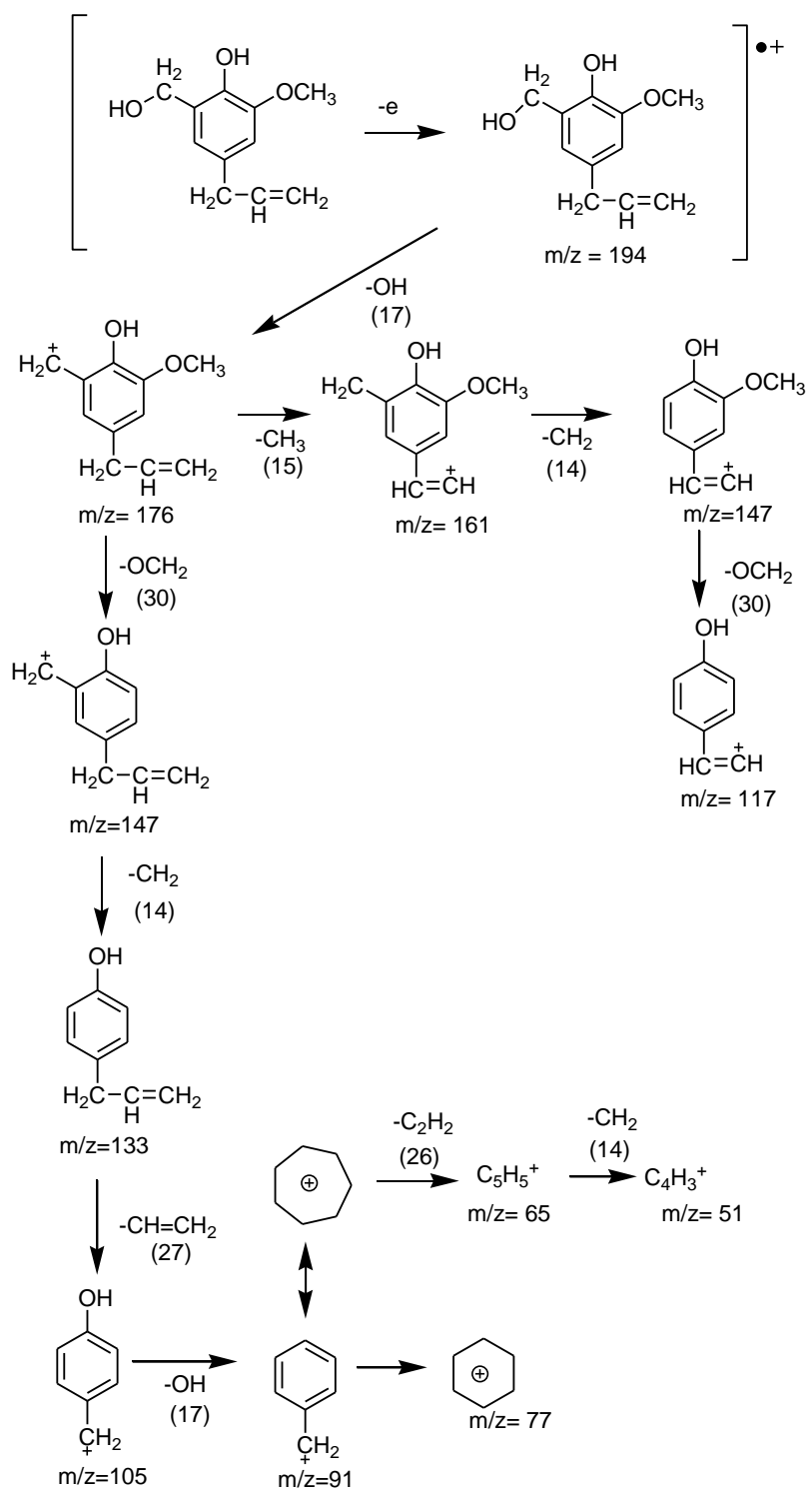

Figure 4.14. Fragmentation pattern of 4-alil-6- (hydroxymethyl) -2-methoxy phenol compound

\section{Conclusion}

Based on the conducted research, for the synthesis compound of 4-alyl-6-(hydroxymethyl)-2methoxy phenol from eugenol through three stages, Mannich reaction, methylation, and nucleophilic substitution it is concluded that:

1. The synthesis of 4-alyl-6-(dimethylamino)methyl-2-methoxy phenol compound from eugenol base material was carried out using Mannich reaction with formaldehyde and dimethylamine in n-heptan solvent under reflux conditions, of which 4.85 grams of eugenol were used, 5.06 grams of 4-alyl-6-(dimethylamino)methyl-2-methoxy phenol $(83 \%)$ was obtained.

2. The synthesis of 6-((N-iodo-N-methyl-N-methyl-N-methylamino) methyl)-4-alyl-2methoxy phenol compound is carried out through a methylation reaction between 4-alyl6-(dimethylamino)methyl-2-methoxy phenol compound and methyl iodide in ethanol 
solvent, from which 4.404 grams of 4-alyl-6- (dimethylamino) methyl-2-methoxy phenol were used as much as 5.66 grams of 6-((N-iodo- $\mathrm{N}$-methyl-N-methyl-N-methylamino) methyl)-4-alyl-2-methoxy phenol (78.15\%) compound.

3. The synthesis of 4-alil-6-(hydroxymethyl)-2-methoxy phenol compound was carried out through nucleophilic substitution reactions with sodium hydroxide, of which 3.621 grams of 6-((N-iodo-N-methyl-N-methyl-N -methylamino) methyl) -4-alyl-2-methoxy phenol compound used, as much as 1.262 grams of 4-alyl-6- (hydroxymethyl)-2methoxy phenol compound $(65.05 \%)$ were obtained.

\section{References}

Kardinan,A.,2005, Tanaman Penghasil Minyak Atsiri,Agromedia Pustaka,Jakarta.

Karanov,E.,Iilev,L.,Alexieva,V., 1995,Synthesis and Plant Growth Regulating Activity of Some Novel 2-Methoxy-4-(1-or2-Propenil)-6-SubstituedPhenol, Bulg.J.Plant Physiol, Vol. 21(4), pp. 39-47.

Kong,X.,Liu,X.,Yang,Y.,2014, Advances in Pharmacological Research Of Eugenol, Curr Opin Complement Alternat Med, Vol. 1.

Kousar, F., Nosheen, S., Jahan, N., 2013, Synthesis anad Biological Activity of Important phenolic Mannich Bases, Asian Journal of Chemistry, Vol. 25(1), pp. 59-62.

Mastelic,J.,Jerkovic,I.,Blazeveic,I.,2008, Comparative Study on the Antioxidant and Biological Activities of Carvacrol,Thymol, and Eugenol Derivatives.J.Agric.Food Chem, Vol. 56, pp. 3989-3996.

Sastrohamidjojo, H., 2004, Kimia Minyak Atsiri,UGM,Yogyakarta.

Suryanto, E. and Anwar, C ., 2008, Sintesis Antioksidan 4,6-dialil-2-metoksifenol dari alil eugenol Melalui Penataan Ulang Claisen, Chem Prog, Vol. 1(1). 